\title{
Effects of Storage Temperatures on the Post-mortem Biochemical Changes in Scallop Adductor Muscle ${ }^{* 1}$
}

\author{
Kaoru Kawashima*2 and Hideaki Yamanaka*: \\ (Received June 18, 1992)
}

\begin{abstract}
Scallop adductor muscle was examined for changes in contents of ATP and its related compounds, arginine phosphate, octopine, arginine, polyamines, and lactic acids during storage at 5,0 , and $-3^{\circ} \mathrm{C}$.

The decrease in ATP and arginine phosphate and the increase in octopine were faster at -3 , 0 , and $5^{\circ} \mathrm{C}$, in that order. During storage, a low level of AMP accumulation, a rapid increase in inosine, and a gradual increase in hypoxanthine were observed. The $\mathrm{K}$ value increased fastest at $-3^{\circ} \mathrm{C}$, and slowest at $5^{\circ} \mathrm{C}$, as opposed to the case of fish and prawn. However, results of sensory evaluation indicated that decomposition progressed fastest at $5^{\circ} \mathrm{C}$. IMP as well as adenosine was detected during storage, suggesting AMP degraded through two pathways. LLactic acid was detected in a small amount, but D-lactic acid was detected in a fairly large amount and accumulated as decomposition progressed. Not only octopine but also D-lactic acid was thought to be the end-products of glycolysis in scallop adductor muscle. As for polyamines, agmatine, putrescine, cadaverine, and tryptamine were detected as decomposition progressed.
\end{abstract}

The consumption of scallop has been increasing considerably since its aquaculture was successfully applied on a commercial basis in the 1970's. Scallop can be utilized as a material in boiled, canned, dried, and smoked products. Furthermore, a large amount of scallop is consumed as a fresh material for a variety of dishes, including such popular dishes as sashimi and sushi. Consequently, retention of the freshness becomes a matter of serious concern, but rather limited information has been available for post-mortem biochemical changes in scallop adductor muscle. Hiltz and Dyer ${ }^{1,2}$ ) reported two major postmortem changes occurring in scallop Placopecten magellanicus muscle: the accumulation of hypoxanthine $(\mathrm{Hx})$, resulting from the degradation of nucleotides and the production of octopine as a principal end-product of the concomitant glycogen degradation. Diverse results were reported concerning ATP-degraded compounds of scallop adductor muscle: $\mathrm{Arai}^{3 \mathrm{3}}$ reported that IMP and $\mathrm{Hx}$ were absent, whereas Nakamura et al. ${ }^{4}$ reported a high concentration of IMP at the early stage of storage, and a gradual increase in $\mathrm{Hx}$ during storage.
In this study, the changes in content of ATP and its related compounds, arginine phosphate, octopine, arginine, polyamines, and lactic acids were examined in scallop adductor muscle during storage at 5,0 , and $-3^{\circ} \mathrm{C}$.

\section{Materials and Methods}

\section{Materials}

Cultured live scallops Patinopecten yessoensis were purchased at the Tokyo Wholesale Market from July to October 1991. Each dissected adductor muscle ( 6 specimens, average $30 \mathrm{~g}$ in weight) was divided into three portions, then stored at 5,0 , and $-3^{\circ} \mathrm{C}$. At regular intervals, about $3 \mathrm{~g}$ of muscle was removed from each portion. The muscle was homogenized in $10 \mathrm{~m} l$ ice-cold $6 \%$ perchloric acid and the suspension was centrifuged at $10,000 \mathrm{rpm}$ for $10 \mathrm{~min}$. The procedure was repeated, and the supernatants were combined. After neutralization with $\mathrm{KOH}$, the supernatant was added to make $25 \mathrm{~m} l$ with distilled water. This solution was subjected to the following analysis.

*1 This study was presented at the annual meeting of Japan. Soc. Sci. Fish., Tokyo, April 1992.

*2 Food Science Laboratory, Faculty of Education, Saitama University, Shimo-ohkubo, Urawa, Saitama 338, Japan (川鸠かほる：埼玉大学教育学部)。

*3 Department of Food Science and Technology, Tokyo University of Fisheries, Konan, Minato, Tokyo 108, Japan（从中笑明：東京水险大学食品生磁学科）。 
Determination of ATP and Its Related Compounds

ATP and its related compounds were determined with high performance liquid chromatograph (HPLC) as reported by Matsumoto and Yamanaka ${ }^{5)}$ with a slight modification: they were eluted with $200 \mathrm{mM} \quad \mathrm{NaH}_{2} \mathrm{PO}_{4}$ (pH 2.9), absorbance at $260 \mathrm{~nm}$.

\section{Determination of Arginine Phosphate}

Arginine phosphate was analyzed with HPLC equipped with a UV-VIS spectrophotometric detector (SPD-6AV, Shimadzu Co.) with absorbance at $205 \mathrm{~nm}$ on the Shim-pack CLC-NH column $(6 \mathrm{~mm} \times 150 \mathrm{~mm}$, Shimadzu Co. $)$ as reported by Matsumoto and Yamanaka. ${ }^{8)}$

\section{Determination of Octopine and Arginine}

Octopine and arginine were determined with HPLC according to the method of Kai et al. ${ }^{7)}$ with a slight modification: octopine and arginine were converted to fluorescent derivatives with benzoin, and then analyzed with HPLC equipped with a fluorescence detector (FLC-6A, Shimadzu Co.) on the Kaseisorb LC ODS-300-5 column $(4.6 \mathrm{~mm} \times 250 \mathrm{~mm}$, Tokyo Kasei Kogyo Co.).

\section{Determination of Polyamines}

Tyramine, putrescine, cadaverine, histamine, agmatine, tryptamine, and spermidine were determined with HPLC according to the method of Yamanaka. ${ }^{8)}$

\section{Determination of Lactic Acid}

L- and D-lactic acid were determined by using L-lactate dehydrogenase (E. C. 1.1.1.27, Boehringer Mannheim Co.) and D-lactate dehydrogenase (E. C. 1.1.1.28, Boehringer Mannheim Co.) according to the method of Noll. ${ }^{\text {p) }}$

\section{Sensory Evaluation}

The degree of freshness of scallop adductor muscle was evaluated by trained sensory panels and classified into three stages mainly based on its odor: acceptable stage (no smell); stage of initial decomposition (faintly putrid smell); stage of advanced decomposition (putrid smell).

\section{Results}

\section{ATP and lts Related Compounds}

The changes in contents of ATP and its related compounds in scallop adductor muscle stored at 5,0 , and $-3^{\circ} \mathrm{C}$ are shown in Figs. 1, 2, and 3.

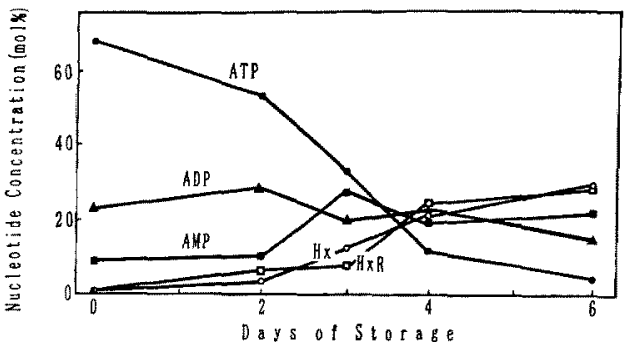

Fig. 1. Changes in percentage distribution of ATP and its related compounds during storage at $5^{\circ} \mathrm{C}$.

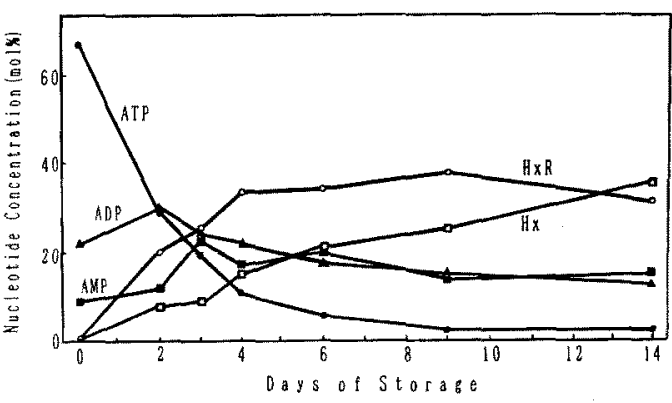

Fig. 2. Changes in percentage distribution of ATP and its related compounds during storage at $0^{\circ} \mathrm{C}$.

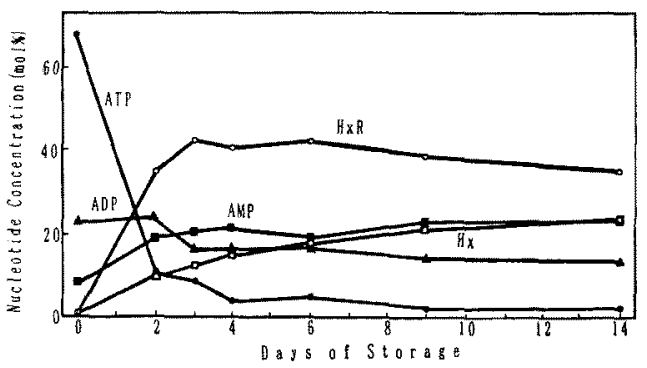

Fig. 3. Changes in percentage distribution of ATP and its related compounds during storage at $-3^{\circ} \mathrm{C}$.

ATP contents immediately after death ranged from 4.2 to $8.8 \mu \mathrm{mol} / \mathrm{g}$ among the 6 specimens, and consisted of a molar ratio of around $70 \%$ of total ATP-related compounds. The average nucleotide profile at the start was $67 \%$ ATP, $23 \%$ ADP, $8 \%$ AMP, traces of IMP, adenosine (AdR), inosine ( $\mathrm{HxR}$ ), and $\mathrm{Hx}$.

During storage at $5^{\circ} \mathrm{C}$, ATP slowly decreased and its concentration reached a $5 \%$ molar ratio of the total ATP-related compounds on the 6th day of storage. On the contrary, ATP 
Table 1. Changes in contents of polyamines in scallop adductor muscle during storage at 5,0 , and $-3^{\circ} \mathrm{C}$

decreased rapidly when stored at $-3^{\circ} \mathrm{C}$, and remained as only a $11 \%$ molar ratio of the total ATP-related compounds even on the 2nd day of storage. The change in ATP content during storage at $0^{\circ} \mathrm{C}$ was intermediate between those at 5 and $-3^{\circ} \mathrm{C}$. With the decrease in ATP, AMP slowly accumulated to around $20 \%$ of the total nucleotide concentration at all the storage temperatures, whereas $\mathbf{H x R}$ increased considerably at $-3^{\circ} \mathrm{C}$, moderately at $0^{\circ} \mathrm{C}$, and slowly at $5^{\circ} \mathrm{C}$. $\mathrm{Hx}$ also increased but at a slower speed than that of HxR. IMP and AdR, which are not shown in Figs. 1, 2, or 3, slowly increased during storage, and the highest concentrations were 2 and $1 \%$ molar ratios of the total ATP-related compounds, respectively. The occurrence of IMP and AdR were confirmed by enzymatic analyses.

\section{Arginine Phosphate}

Figure 4 shows the changes in content of arginine phosphate in scallop adductor muscle during storage. Immediately after death, the content of arginine phosphate was $5 \mu \mathrm{mol} / \mathrm{g}$. Arginine phosphate decreased noticeably to al-

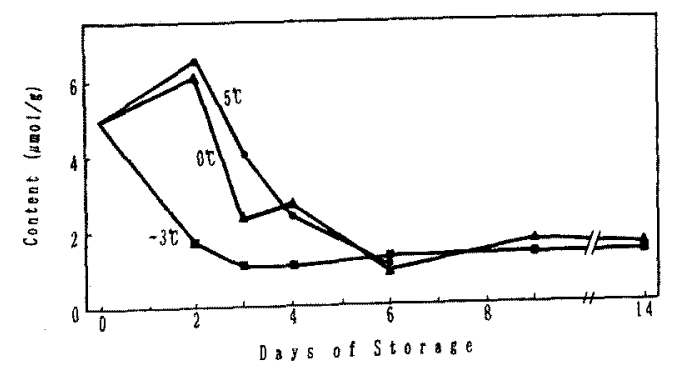

Fig. 4. Changes in content of arginine phosphate during storage. most $1 \mu \mathrm{mol} / \mathrm{g}$ on the $3 \mathrm{rd}$ day of storage at $-3^{\circ} \mathrm{C}$, then maintained this level until the 14th day of storage. When stored at 5 or $0^{\circ} \mathrm{C}$, it increased to little more than $6 \mu \mathrm{mol} / \mathrm{g}$ on the 2 nd day of storage, then rapidly decreased to $1 \mu \mathrm{mol} / \mathrm{g}$ on the 6 th day of storage.

\section{Octopine and Arginine}

The changes in contents of octopine and arginine in scallop adductor muscle during storage are shown in Figs. 5 and 6 . Immediately

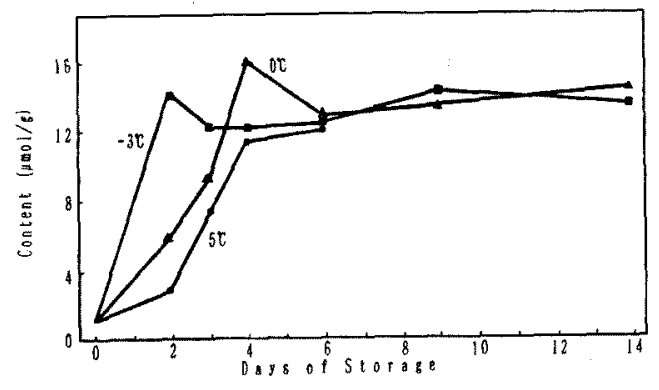

Fig. 5. Changes in content of octopine during storage.

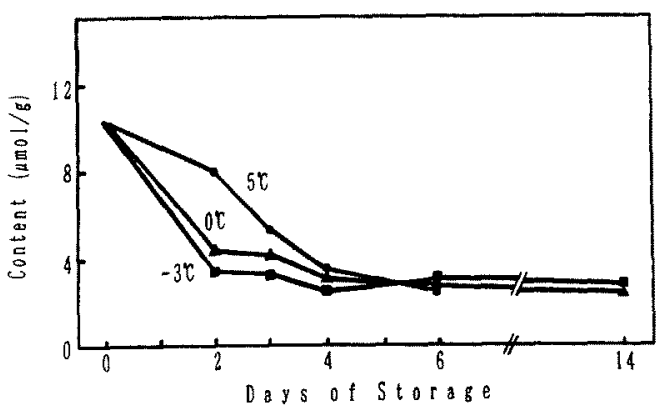

Fig. 6. Changes in content of arginine during storage. 


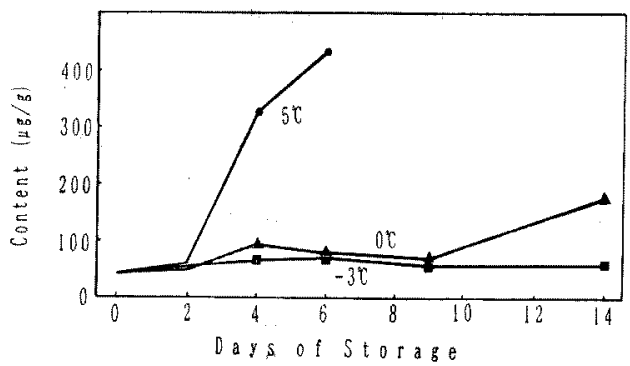

Fig. 7. Changes in total amounts of p-lactic acid and L-lactic acid during storage.

after death, the contents of octopine and arginine were $1 \mu \mathrm{mol} / \mathrm{g}$ and $10 \mu \mathrm{mol} / \mathrm{g}$, respectively. Octopine increased during storage, whereas arginine decreased. The rate of octopine increase and of arginine decrease was largest at storage at $-3^{\circ} \mathrm{C}$, and smallest at storage at $5^{\circ} \mathrm{C}$. The contents of octopine and arginine reached 12 and $3 \mu \mathrm{mol} / \mathrm{g}$ respectively regardless of the storage temperatures.

\section{Polyamines}

Table 1 shows the changes in contents of polyamines in scallop adductor muscle during storage. Initially, polyamines were absent. Putrescine (PUT), cadaverine (CAD), agmatine (AGM), and tryptamine (TPM) were detected in small amounts after 3 days of storage at $5^{\circ} \mathrm{C}$, then they gradually increased. When stored at $0^{\circ} \mathrm{C}$, AGM was detected on the 6th day of storage, and on the 9th day, PUT and CAD were also detected. Only a trace of AGM was detected on the 14 th day of storage at $-3^{\circ} \mathrm{C}$.

\section{Lactic Acid}

The changes in the total amount of D- and L-lactic acid in scallop adductor muscle during storage are shown in Fig. 7. The total amount of D- and L-lactic acid was $40 \mu \mathrm{g} / \mathrm{g}$ at the beginning, and D-lactic acid consisted of around $80 \%$ of the total. The D-lactic acid content increased noticeably after 2 days of storage at $5^{\circ} \mathrm{C}$, and increased moderately after 9 days of storage at $0^{\circ} \mathrm{C}$, whereas the L-lactic acid content showed almost no change. On the other hand, both $D^{-}$ and L-lactic acid contents remained at the same level when stored at $-3^{\circ} \mathrm{C}$.

\section{Sensory Evaluation}

Results of sensory evaluation are summarized in Fig. 8, together with the changes in the $\mathrm{K}$ value.

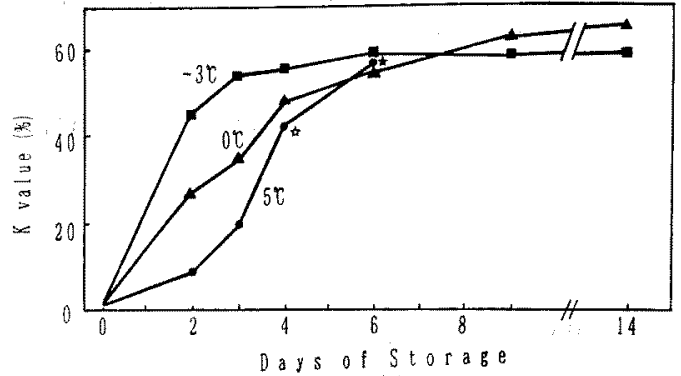

Fig. 8. Changes in $\mathbf{K}$ value and sensory rating during storage. Symbols used are: $\hat{s}$, evaluated as initial decomposition; $\star$, evaluated as advanced decomposition.

After 4 days' storage at $5^{\circ} \mathrm{C}$, scallop adductor muscle was evaluated to be at the stage of initial decomposition, conversely no evidence of decomposition was detected during the storage at 0 and $-3^{\circ} \mathrm{C}$ for 14 days.

\section{Discussion}

ATP degradation, along with the decrease in arginine phosphate and the increase in octopine, was fastest at $-3^{\circ} \mathrm{C}$, followed in order by those at $0^{\circ} \mathrm{C}$ and at $5^{\circ} \mathrm{C}$. Faster ATP degradation at a lower storage temperature has also been observed for plaice, ${ }^{10,11)}$ red sea bream, ${ }^{12-14}$ and kuruma prawn. ${ }^{5)}$ Watabe et al. ${ }^{15)}$ concluded that this phenomenon occurs because $\mathrm{Ca}^{\text {a+ }}$ uptake ability of sarcoplasmic reticulum decreases at a lower storage temperature, resulting in an increase in $\mathrm{Ca}^{2+}$ concentration inside myofibrils. Then, the increased $\mathrm{Ca}^{2+}$ ion activates myofibrillar $\mathrm{Mg}^{2+}$-ATPase and thus accelerates ATP consumption. The same mechanism would be applicable to scallop adductor muscle.

As a result of the ATP degradation, IMP generally accumulates in fish and AMP in molluscs. Further degradation to $\mathrm{HxR}$ or to $\mathrm{Hx}$ is very slow, but after reaching the stage of initial decomposition, a marked increase in $\mathrm{Hx}$ occurs because of the microbial growth. ${ }^{16)}$ Accordingly the $\mathrm{K}$ value, ${ }^{17)}$ a freshness index defined as the molar ratio of $\mathrm{HxR}$ plus $\mathrm{Hx}$ to the total of ATPrelated compounds, increases faster during storage at higher temperature, which allows active growth of microbes. On the contrary, in the case of scallop adductor muscle, AMP accumulation was fairly low, and further degradation to $\mathrm{HxR}$ and $\mathrm{Hx}$ was observed from the beginning. Therefore, the $K$ value increased most rapidly when stored at 
$-3^{\circ} \mathrm{C}$, where ATP degradation was fastest. Similar changes in the $\mathrm{K}$ value were reported for itayagai scallop Pecten albicans, ${ }^{18)}$ where the $\mathrm{K}$ value increased faster at -3 and $0^{\circ} \mathrm{C}$ than at 5 and $10^{\circ} \mathrm{C}$.

On the 4th day of storage at $5^{\circ} \mathrm{C}$, scallop adductor muscle was evaluated to be at the stage of initial decomposition when the $\mathrm{K}$ value was $42 \%$. On the other hand, scallop adductor muscle stored at $-3^{\circ} \mathrm{C}$ was evaluated to be acceptable even on the 14th day of storage, but the $K$ value was already $45 \%$ on the 2 nd day of storage. Thus, it is considered that the $\mathrm{K}$ value as a freshness index could not be applicable to scallop adductor muscle.

Arai $^{\left.1{ }^{19}\right)}$ has reported the presence of adenosine deaminase with high activity and the absence of AMP deaminase, which resulted in absence of IMP in scallop adductor muscle. In contrast, Nakamura et al., ${ }^{4)}$ Sakamoto et al., ${ }^{20)}$ and Nagamine et al..$^{.11}$ have detected IMP. In this study, though at low levels, both AdR and IMP were detected during storage. The presence of AdR and IMP were independently confirmed by enzymatic analyses. From this result, AMP was considered to degrade to HxR through two pathways.

Arginine phosphate in molluscs, like creatine phosphate in fish, is used to generate ATP from ADP. Arginine phosphate in scallop adductor muscle decreased with ATP decrease, whereas arginine phosphate in prawn or creatine phosphate in fish ${ }^{11,14}$ decreased to certain levels prior to the begining of ATP decrease.

A fairly large amount of D-lactic acid and a small amount of L-lactic acid were detected at the beginning, then D-lactic acid accumulated as decomposition progressed. L-lactic acid is an endproduct of glycolysis in vertebrates, but in molluscs, octopine ${ }^{2,22}$ ) has been said to accumulate instead of L-lactic acid. The present study confirmed that both octopine and D-lactic acid accumulated. Therefore, the end-products of glycolysis in scallop adductor muscle were supposed to be both D-lactic acid and octopine. When Grieshaber and Gäde ${ }^{23)}$ argued the absence of lactic acid in scallop Pecten Jacobaeus adductor muscle under the anaerobic condition, they determined lactic acid by using lactate dehydrogenase (E. C. 1.1.1.27), which is L-lactate dehydrogenase. That was why they could not detect D-lactic acid. Baldwin et al. ${ }^{24}$ have reported that anaerobic stress led to accumulation of $\mathrm{D}$-lactic acid and tauropine in the foot and adductor muscle of New Zealand abalone Haliotis iris. The mechanism of D-lactic acid formation in shellifish post mortem is of great interest.

Polyamine formation, as well as D-lactic acid accumulation, occurred as decomposition progressed, and accordingly showed a reverse temperature dependency to ATP degradation.

\section{References}

1) D. F. Hiltz and W. J. Dyer: Principal acid-soluble nucleotides in adductor muscie of the scallop (Placopecten maghellanicus) and their degradation during postmortem storage in ice. J. Fish. Res. Bd. Can., 27, 83-92 (1970).

2) D. F. Hiltz and W. J, Dyer: Octopine in postmortem adductor muscle of the sea scallop, Placopecten maghellanicus. J. Fish. Res. Bd. Can., 28, $869-874$ (1971).

3) K. Arai: Acid-soluble nucleotides in muscle of marine invertebrates I. Effects of storing temperature upon the content of muscular nucleotides of some seashells (1). Bull. Fac. Fish., Hokkaido Univ., 11, 67-72 (1960).

4) K. Nakamura, Y. Fujii, and S. Ishikawa: Postmortem changes in the amounts of glycogen and ATP in adductor muscle of scallop. Bull. Tokai Reg. Fish. Res. Lab., 84, $21-$ 29 (1976).

5) M. Matsumoto and H. Yamanaka: Post-mortem biochemical changes in the muscle of kuruma prawn during storage and evaluation of the freshness. Nippon Suisan Gakkaishi, 56, 1145-1149 (1990).

6) M. Matsumoto and H. Yamanaka: Studies on rigor-mortis of kuruma prawn muscle. Nippon Suisan Gakkaishi, 57, 2121-2126 (1991).

7) M. Kai, T. Miyazaki, and Y. Ohkura: High performance liquid chromatographic measurement of guanidino compounds of clinical importance in human urine and serum by pre-column fluoresence deriveration using benzoin. $J$. Chromatgr., 311, 257-266 (1984).

8) H. Yamanaka: Changes in polyamines and amino acids in scallop adductor muscle during storage. J. Food Sci., 54, 1133-1135 (1989).

9) F. Noll: in "Methods of Enzymatic Analysis" (ed. by $\mathbf{H}$. U. Bergmeyer), 3rd ed., Verlag Chemie, Weinheim, 1984, vol. VI, pp. 582-588.

10) M. Iwamoto, H. Yamanaka, S. Watabe, and K. Hashimoto: Effect of storage temperature on rigor-mortis and ATP degradation in plaice Paralichthys olivaceus muscle. J. Food Scl., 52, 1514-1517 (1987).

11) M. Iwamoto, H. Yamanaka, H. Abe, H. Ushio, S. Watabe, and $K$. Hashimoto: ATP and creatine phosphate breakdown in spiked plaice muscle during storage, and activities of some enzymes inyolved. J. Food Sci., 53, 1662-1665 (1988).

12) M. Iwamoto, H. Ioka, M. Saito, and H. Yamanaka: Relation between rigor mortis of sea bream and storage temperatures. Nippon Stuisan Gakkaishi, 51, 443-446 (1985).

13) M. Iwamoto and $H$. Yamanaka: Remarkable differences in rigor mortis between wild and cultured specimens of the red sea bream Pagrus major. Nippon Suisan Gakkaishi, 52, 275279 (1986).

14) M. Iwamoto, H. Yamanaka, H. Abe, S. Watabe, and K. Hashimoto: Rigor-mortis progress and its temperaturedependency in several marine fishes. Nippon Suisan Gakkaishi, 56, 93-99 (1990)

15) S. Watabe, H. Ushio, M. Iwamoto, H. Yamanaka, and K. Hashimoto: Temperature-dependency of rigor-mortis of fish muscle: myofiblillar $\mathrm{Mg}^{2+}$-ATPase activity and $\mathrm{Ca}^{2+}$ uptake by sarcoplasmic reticulum. J. Food Sci, 54, 1107 1115 (1989).

16) M. Matsumoto and H. Yamanaka: Influences of antibiotics 
chloramphenicol on post-mortem biochemical changes in the muscle of kuruma prawn during storage. Nippon Sulsan Gakkaishl, 57, 2291-2297 (1991).

17) H. Uchiyama, S. Ehira, H. Kobayashi, and W. Shimizu: Significance in measuring volatile base and trimethylamine nitrogen and nucleotides in fish muscle as indices of freshness. Nippon Suisan Gakkaishi, 36, 177-187 (1970).

18) M. Iwamoto, H. Yamanaka, S. Watabe, and K. Hashimoto: Changes in ATP and related breakdown compounds in the adductor muscle of "itayagai" scallop Pecten albicans during storage at various temperatures. Nippon Suisan Gakkaishi, 57, 153-156 (1991).

19) K. Arai: Acid-soluble nucleotides in muscle of marine invertebrates V. Degradation of adenylic acid in the muscles of scallop and abalone. Bull. Fac. Fish., Hokkaido Univ., 17, 91-98 (1966)

20) M. Sakamoto, Y. Fujii, and K. Nakamura: Changes of the components in adductor muscle of scallop during storage. Bull. Tokal Reg. Fish. Res. Lab., 75, 107-118 (1973).

21) H. Nagamine, T. Yamahi, H. Matsubara, and $Y$. Fukuda: Changes in freshness of live scallop during cold storage. Aomoriken Suisankakoukenkyujo Shikenkenkyu Hokoku 1987, 22-27 (1987). (in Japanese)

22) M. Grieshaber and G. Gäde: The biological role of octopine in the squid Loligo vulgaris. J. Comp. Physiol, 108, 225-232 (1976).

23) M. Grieshaber and G. Gäde: Energy supply and formation of octopine in the adductor muscle of the scallop, Pecten Jacobaeus (Lamarck). Comp. Biochem. Physiol., 58B, 249252 (1977).

24) J. Baldwin, R. M. G. Wells, M. Low, and J. M Ryder: Tauropine and b-lactate as metabolic stress indicators during transport and storage of live paua, (New Zealand abalone) (Haliotis iris). J. Food Sci, 57, 280-282 (1992). 